\title{
Psychiatry: a contracting specialty?
}

\section{Recent government policy and legislation}

\author{
Gregory J.R. Richardson
}

\begin{abstract}
Psychiatric services dellvered outside agreed contracts between purchasers and providers will not be paid for. Reduced income will then mean reduced services. This article describes how psychiatrists might understand and address the contracting issues for their service, so that they effectively involve themselves in the contracting process in their locality, and so maintain the services for their patients.
\end{abstract}

The Department of Health recently produced The Health of the Nation Key Area Handbook on Mental Illness (NHSME, 1993) to drive the structuring of services for the mentally ill. It is a comprehensive guide to developing a mental health strategy, with an emphasis on 'local' in five of its 13 chapter headings. Hence all psychiatrists are required to look at the provision of services locally and the requirements of local purchasers, and how they are interlocked in the contracting process.

\section{The contracting process}

The contracting process includes the following.

(a) Purchasers' responsibility for the assessment of need, not only by identifying people with mental health problems but also the needs of agencies working with the mentally ill, so that they purchase in collaboration with organisations such as social services and voluntary organisations; purchasers also need to understand effective interventions for mental health problems to ensure they purchase health giving options.

(b) Purchasers' prioritisation of the need they have identified, as they are unlikely to be able to purchase it all.

(c) The commissioning process in which the purchasers discuss their requirements with prospective providers and choose what service to purchase at what price. These discussions should drive the contracting process and make it work, for they will prevent purchasers making ridiculous demands which are not practical and they cannot monitor, and providers deciding what they will provide on the basis of what they have, rather than on what their population needs. Good purchaser/provider interaction and negotiation at this stage will ensure a high standard for the subsequent service. Poor negotiation will lead to misunderstanding, recriminations and a demoralised service.

(d) The provision of services, which may become more specific as purchasers become more sophisticated. For a moderate sized district, a multidisciplinary, multispeciality service should be provided to deal with the severity and disparity of illnesses and behaviours of the mentally ill in all age groups. The service should also work with, and provide support for other agencies working with mentally ill people.

(e) The purchaser's evaluation of the service by measurements of health gain and achievements of the agreed aims and objectives of the service.

\section{The psychiatrist's dilemma}

As the providers in this process, psychiatrists are at risk of experiencing conflicting demands. The NHS Management Executive document on the extension of GP fund-holding from 1 April 1993 (NHSME, 1992) makes it clear in its section on mental health services that "mental health services are generally provided by integrated multidisciplinary mental health teams", and that GP fundholders "will need to consider the team approach . . . to ensure that the full range of expertise can be brought to bear on the most seriously ill patients and to maximise the chances of their being managed in the community without recourse to hospital admission". Hence "the delivery of psychiatric services through the NHS mental health team with its strong ties with SSDs (social services departments) is seen as central to good practice". Such words might be acknowledged by an area purchasing authority, which has responsibility for providing a comprehensive service for a large population. Such an authority may perceive a community mental 
health team as the most effective way of providing such a service and a block contract the simplest way of purchasing it. However, GP fundholders may consider that, although they appreciate such a service may be necessary for certain patients, a high priority for them is to obtain the services of a named professional for a specific opinion or treatment, or both.

This double message from different purchasers about how mental health services should be structured echoes the dichotomy between the mental health professionals who believe their first responsibility is to the severely psychiatrically ill (Sims, 1993), who may not be on a general practitioner's list, and are at high risk of becoming inaccessible cardboard city inhabitants, and the GPs whose priority is their patients whose lives are being seriously hindered by psychological problems.

As a response to these conflicting pressures, a 'product list' of services for GPs may have to be devised so that assessment and treatment packages by individual mental health professionals are priced separately from team assessments and treatments. To base contracting on such a list will probably require cost per case contracts, and some GPs would like the costing broken down further into cost per attendance. These are expensive choices because of administrative costs and the costs required to cover the consequences of uncertainty of work-load; fundholders being able to change their purchasing habits rapidly and unpredictably, which is their reward and the major threat to a cohesive mental health strategy. It may be possible to amalgamate certain 'products' into a cost/volume contract, with working advantages such as a community psychiatric nurse being contracted for a set number of sessions to a particular practice, and then providing a liaison function between that practice and the sector mental health team.

At present it is difficult to say who the major purchasers in the future will be. The GP fundholders are causing providers to tinker at the edges, but the decisions of health authorities could bluntly strike at the core of services, because they are responsible for considerably larger sums of money. Whether or not fundholders, family health service authorities and health authorities purchase cojointly, they are likely to become more sophisticated in their requirements, and hence the need to have the different aspects of our services more precisely costed.

\section{Operational issues}

Once this gearing to the market process has started, the boundaries of our sectors and districts start to blur. The district becomes an amoeba with pseudopodia extending in some directions and withdrawing in others. This means certain operational issues will need to be addressed, for example the following.

(a) Popular mental health professionals will receive more work than they can handle. and unpopular mental health professionals will be under-utilised. To some extent differential waiting lists may act as a balance here. The need for sectorised services and speciality work, for example in psychotherapy or rehabilitation, will also tend to restrict choice. However, if purchasers are so dissatisfied with a particular part of the service that they decide to purchase elsewhere, the professionals in that service no longer have a job. Conversely, mechanisms will have to be developed whereby staff who take on more work and expand the work of the trust are rewarded, and staff are taken on to deal with the extra work-load.

(b) The provision of back-up facilities, such as in-patient beds to GPs from outside the old district who purchase out-patient facilities, will have to be renegotiated with the appropriate purchasing health authority. Similarly such facilities should be withdrawn from fund-holders who do not make a commitment to purchasing local out-patient and community services. In-patient provision should therefore be geared to those practices which make a clear statement of intent about purchasing services from the local provider. Similarly locally based facilities, such as bases for community mental health teams or day centres, should not be provided for uncommitted practices.

\section{Action required}

What is required now is:

(a) to clarify and separate the many different aspects of the psychiatrists' work-loads so that costs can be allocated appropriately; for example, by clarifying the percentage of time spent in general psychiatry and how much with each special interest, and then further by breakdown into time spent on in-patient and out-patient work. and then dividing that by the in-patients and out-patients seen, in order to calculate costs per case. Follow-up appointments, letter writing, attendance at case conferences etc must all be included to ensure costs are accurately calculated. Travelling time and consultation work may have to be priced separately and 
added to the out-patient costs of individual patients. Education, administrative and audit times are part of the overheads which will be added to costs proportionately. Considerable help and guidance from contracting departments will be required

(b) to ensure we meet our GP colleagues to negotiate contracts which reflect our understanding of each other's aspirations and difficulties, and to understand the consequences of the contracts we agree

(c) to develop trust-wide "protocols and referral criteria so that there is a shared understanding of when referral is appropriate", and of how the sector mental health team functions. "GPs will need to determine in discussion with consultants precisely where individual responsibilities lie since arrangements will vary between different mental health care teams" (NHSME, 1992)

(d) to monitor referrals of patients of GPs who are referred by other agencies such as social services, and negotiate how these services are to be paid for

(e) to ensure we understand GPs' dissatisfactions with the service, before they build penalty clauses into our contracts.

The message is simple: Contract or Contract.

\section{References}

National Health Service Management Executtve (1992) Mental health services. In Guidance on the Extension of the Hospital and Community Health Services Elements of the GP Fundholding Scheme from 1 Aprll 1993. NHSME EL (92) 48. London: NHSME.

- (1993) Key Area Handbook-Mental Illness. London: NHSME.

SimS, A. (1993) General practitioner fundholding and psychiatric practice. Psychiatric Bulletin. 17, 193-195.

Gregory J.R. Richardson, Consultant in Child and Adolescent Psychiatry, and Consultant Adviser, Medical Services, York Health Services NHS Trust, York YO3 7BY 